\title{
Can OSPREY rise up from its watery grave?
}

London. The developers of OSPREY, the world's first commercial wave power-station, appear unfazed by its sinking off the Scottish coast in storm conditions less than a month after its launch on 2 August.

They have pledged to build its successor, OSPREY 2, by next summer - despite renewed doubts about the device's ability to withstand the region's harsh weather.

OSPREY stands for Ocean Swell Powered Renewable Energy. Funded by private companies and a $£ 435,000$ (US\$700,000) grant from the European Union's Joule programme for research into non-nuclear energy, it was designed to generate electricity for 2,000 homes for 25 years.

As such, OSPREY was billed by its supporters as a sharp riposte to those - including the British government - who have dismissed wave energy as unsound, uneconomic and, therefore, unworthy of state support (see Nature 376, 544; 1995).

But less than two weeks after its launch, continued buffeting by waves had led to holes in OSPREY's ballast tanks. The structure then caught the tail end of Hurricane Felix, and by 26 August it began to sink.

Despite this, Applied Research and Technology (ART), the Inverness-based engineering company that designed and funded the £2-million generator, described the incident as just an unfortunate setback.

Allan Thomson, the company's managing director, says he intends to push ahead with the project which, he says, should be completed "in the next six months". He expects it to be funded out of the insurance money received for the sunken OSPREY. "Nothing will change," says Thomson. "All our backers are still with us. The market interest from maritime countries continues to grow. There will always be hurdles, but you just have to cross them."

Thomson refuses to speculate on why OSPREY sank. The generator was insured with Lloyds, and an assessor's report is expected shortly. But Thomson strongly denies that the sinking was the result of any flaw in OSPREY's design, which he says will remain unchanged for OSPREY 2. "The design was good. The installation went like clockwork. We are not likely to change the design. But we will speed up the installation [for OSPREY 2]."

Prior to launch, critics had also questioned the decision to launch the OSPREY off Scotland's north coast. Donald McDonald, an electrical engineer at Imperial College, London, was reported as saying that the weather was sufficiently rough in winter that only granite lighthouses stood any chance of staying upright. But Thomson says

that the coast off northern Scotland has excellent wave conditions. "It is the perfect location. I have absolutely no regrets".

All of OSPREY's private backers including British Steel, GEC Alsthom and Scottish Hydro-Electric - remain firmly committed to the scheme. But the position of officials responsible for the EU's Joule programme, which recently awarded ECU800,000 (US\$1.05 million) to the

IMAGE UNAVAILABLE R COPYRIGHT REASONS

\begin{abstract}
That sinking feeling: the power generator after last month's launch (above) and shortly before disappearing under the waves off Scotland's northern coast (right).
\end{abstract}

hub for a wave generator's two-tonne turbine blade, remains unclear.

Wolfgang Palz, of the renewable energy division of the European Commission's Science, Technology and Research directorate, says any future decision to fund an OSPREY project will take the sinking incident into account. "That does not mean the answer will be an immediate, 'no'," he emphasizes. "Our technical experts will take a look, make an assessment and draw the appropriate conclusions."

But Palz also maintains that OSPREY's fate will not affect the Joule programme's support for the concept of wave energy. "Wave energy should have its chance; it is at an early stage and has huge potential" he says. "Accidents happen, as we have to deal with a hostile environment. It is normal for things not to go as much to plan as they do for solar projects, for example."

Wave energy research in the United Kingdom has been largely privately funded since 1983, when the government pulled the plug having spent nearly $£ 17$ million over 10 years unsuccessfully trying out 300 different concepts of harnessing energy from waves. Between 1985 and 1993, the government spent just $£ 2$ million, mainly to support work on a $75 \mathrm{~kW}$ oscillating water column device developed by the Queens University of Belfast.

Desearchers at the University of Edinburgh, where much of Britain's wave energy research has been carried out, accused the government of withdrawing at a critical period when a breakthrough looked increasingly likely.

But a report on wave energy published in 1992 by the Department of Trade and Industry, which is now responsible for UK energy policy, concluded that the main devices developed were unlikely to generate electricity competitively in the short to medium term.

The review recommended that the freeze on funding for wave studies remain, on the grounds that "the technical performance and reliability of many components over a long term in a marine environment should be demonstrated".

A report produced earlier this year as part of the government Technology Foresight exercise reached a similar conclusion, recommending merely that a "watching brief" be kept on both wave and tidal energy sources.

Ehsan Masood

\section{Greenpeace under fire on Brent Spar coverage}

London. Television news editors last week admitted that they had been manipulated by the environmentalist group Greenpeace over the coverage of the Shell Oil Company's abandoned plans to dump the Brent Spar oil platform in the North Sea. This was partly, they say, because "seductive" pictures make better television than good science.

"Greenpeace is the best and most professional pressure group," said Richard Sambrook, a senior BBC news editor, during an address to last month's Edinburgh television festival. "It can target more resources at one story than a news organization can, and provide better, more compelling, more frequent coverage," he admitted.

Sambrook said that the BBC tried to redress this by broadcasting reports analysing scientific arguments, explaining the context, trying to give the bigger picture. "But such attempts at retaining our editorial propriety are not as memorable as seductive pictures from the North Sea."

$\mathrm{He}$ added that reporting issues such as the proposed dumping of the Brent Spar was made more difficult for news editors by the conflicting scientific claims of either side, including the fact that "even independent scientists" find some of these issues difficult to agree upon. "We are lay men and women caught up in the crossfire of a battle of statistics."

But in a newspaper article, Chris Rose, programme director of Greenpeace UK, claims that Sambrook's comments are "patently untrue". 